\title{
The relationship between social participation and social skills of pupils with an intellectual disability: A study in inclusive classrooms
}

\author{
Ariana Garrote ${ }^{1}$ \\ University of Zurich, Switzerland \\ Article received 5 August / revised 31 October / accepted 1 November / available online 26 January
}

\begin{abstract}
Researchers claim that a lack of social skills might be the main reason why pupils with special educational needs (SEN) in inclusive classrooms often experience difficulties in social participation. However, studies that support this assumption are scarce, and none include pupils with an intellectual disability (ID). This article seeks to make an important contribution to this discussion. The social skills and social participation of pupils with ID and their typically developing (TD) peers in 38 general education classrooms were assessed with multidimensional instruments. The analyses indicate that the majority of pupils with ID were not popular but were socially accepted and had friends. Additionally, no significant relationship was found between social skills and the social participation of pupils with ID, although such pupils had lower levels of social skills compared with their TD peers. Thus, it appears that pupils with ID do not require high levels of social skills to be befriended or accepted by classmates. In contrast, social skills were associated with popularity and social acceptance within the group of TD pupils. In fact, popular TD pupils had the highest level of social skills. These findings support the assumption that in addition to low levels of social skills, there must be other mechanisms that influence the social participation of pupils with ID in inclusive classrooms.
\end{abstract}

Keywords: Social skills; social participation; special educational needs; sociometric status; friendship

\footnotetext{
${ }^{1}$ Contact information: Ariana Garrote, Department of Educational Sciences, University of Zurich, Freiestrasse 36, 8032 Zürich, Switzerland. E-mail: agarrote@ife.uzh.ch DOI: http://dx.doi.org/10.14786/flr.v5i1.266
} 


\section{Introduction}

Children learn a wide range of social behaviours and skills in their social interactions with peers. Their experiences within this social context influence their socio-emotional development and their later adjustment during adulthood (Rubin, Bukowski, \& Parker, 2006). This phenomenon is one reason why the UN Convention recommends the social participation of pupils with disabilities in the community and the classroom (United Nations, 2006). Consequently, an increasing tendency to include pupils with special educational needs (SEN) in general education schools is observed internationally (Koster, Nakken, Pijl, \& van Houten, 2009; Pijl, Frostad, \& Flem, 2008; Ruijs \& Peetsma, 2009). However, the mere presence of these pupils in general education classrooms does not automatically result in successful social participation. Pupils with SEN are less involved in social interactions with peers, less accepted and more frequently rejected than their typically developing (TD) peers (Avramidis, 2013; Estell et al., 2008; Feldman, Carter, Asmus, \& Brock, 2015; Garrote, 2016; Grütter, Meyer, \& Glenz, 2015; Huber, 2006; Koster, Pijl, Nakken, \& van Houten, 2010; Nepi, Fioravanti, Nannini, \& Peru, 2015; Pijl \& Frostad, 2010; Rotheram-Fuller, Kasari, Chamberlain, \& Locke, 2010).

On one hand, studies demonstrate that TD pupils do not like to work with their low-achieving peers, including peers with SEN (Huber \& Wilbert, 2012; Krull, Wilbert, \& Henneman, 2014; Monchy, Pijl, \& Zandberg, 2004). Thus, teachers tend to avoid mixing pupils with SEN and their TD peers for certain activities, such as group work, and therefore, pupils with SEN lack shared learning experiences. In fact, Feldman et al. (2015) found that due to their teacher's planning students with severe disabilities, included in general education classrooms, were not present in most of the classes and were not physically close enough to their peers if present. Therefore, pupils with SEN not only miss opportunities to interact and to become involved in social relationships but also do not receive the chance to learn and practice social skills with their TD peers.

On the other hand, researchers hypothesize that the difficulties pupils with SEN experience with social participation may be due to their lack of social skills (e.g., Avramidis, 2013; Huber \& Wilbert, 2012; Pijl et al., 2008; Schwab, Gebhardt, Krammer, \& Gasteiger-Klicpera, 2015). However, the relationship between the social participation of pupils with SEN and their social skills has not been thoroughly studied, and the concepts of social participation and SEN vary from study to study. Typically, the samples of pupils with SEN are heterogeneous and include pupils with different needs and problems (e.g., children with behavioural problems, with learning disabilities, or with physical disabilities). Therefore, valid knowledge on the topic is lacking.

This study contributes to closing this research gap. It investigates to what extent the social participation of pupils with SEN in general education classrooms is associated with their social skills. Social participation and social skills were measured in a large sample of pupils with a diagnosed intellectual disability (ID) and their TD peers. This study contributes the following novelties to the literature. First, although there are a number of studies investigating the social participation of pupils with SEN enrolled in inclusive classrooms, there is little knowledge about influencing factors. Thus, this study focusses on social skills, which are assumed to influence the social participation of pupils with SEN. Second, the heterogeneity of the group of pupils with SEN was decreased by limiting the sample to pupils with ID. Third, social participation was measured using a multidimensional approach that included aspects of social relationships (i.e., friendships) and social acceptance (i.e., popularity and rejection), which are two important dimensions of social participation (Bossaert, Colpin, Pijl, \& Petry, 2013; Koster et al., 2009). Fourth, to measure social skills, an empirically well-studied scale with a theoretical foundation was used. Fifth, until now, no findings have been reported regarding the relationship between the social participation and the social skills of pupils with ID in inclusive classrooms. Finally, this study shall give new insights about processes influencing social participation in inclusive classrooms, to derive important implications for further research and for the development of suitable interventions. 


\subsection{Social skills}

There is no commonly accepted concept of social skills (or competences). However, there is consensus regarding the connection between social skills and successful social interactions as well as the ability to establish and maintain positive social relationships. Socially competent individuals are described as being able to use social interactions to satisfy their goals and needs while considering the needs and goals of others (Groeben, Perren, Stadelmann, \& Klitzing, 2011; Perren, Forrester-Knauss, \& Alsaker, 2012; RoseKrasnor, 1997). This definition differentiates between social skills that are important for the self and social skills that are oriented towards the others. Malti and Perren (2016) term these two dimensions of social skills self- and other-oriented. Initiating and maintaining social interactions, leadership skills and the ability to set limits with peers are considered to be self-oriented skills because they aim at satisfying one's own needs. Other-oriented social skills, such as helping, caring, and cooperating, are based on considering the interests and benefits of others in social interactions.

Whereas deficits in self- and other-oriented social skills have been associated with negative peer relations, peer rejection, and victimization (Bellini, Peters, Benner, \& Hopf, 2007; Perren et al., 2012; Malti \& Perren, 2016; Henricsson \& Rydell, 2006), engaging in prosocial behaviour and being able to initiate social interactions can help children become positively involved with peers (Fabes, Martin, \& Hanish, 2009; Henricsson \& Rydell, 2006; Perren, Argention-Groeben, Stadelmann, \& Klitzing, 2016; Rubin et al., 2006).

\subsection{Social skills of pupils with SEN}

There is evidence that certain groups of pupils with SEN are less socially skilled than TD children (Gresham \& MacMillan, 1997). For example, pupils with autism spectrum disorders (ASD) have difficulties with self-oriented social skills, such as initiating social interactions, which places them more at risk of being socially isolated (Bellini et al., 2007). However, intervention studies have demonstrated that these children can benefit from the supportive behaviour of their TD peers with respect to the development of social interaction skills (Camargo et al., 2014; Whalon, Conroy, Martinez, \& Werch, 2015). In addition, engaging in other-oriented social skills, such as cooperative and prosocial behaviour, can also have a positive impact on the social participation of pupils with ASD (Kamps et al., 2002). Similar results have been found for pupils with intellectual disabilities (Goldstein, English, Shafer, \& Kaczmarek, 1997), learning disabilities (Kavale \& Forness, 1996), and behavioural problems (Frederickson \& Turner, 2003).

However, few studies have investigated the relationship between social skills and the social participation of pupils with SEN, and the findings are ambiguous. For example, Frostad and Pijl (2007) found a weak relationship between the social skills (cooperative behaviour and empathy) and the social position (acceptance, friendships and membership in a subgroup) of pupils with SEN. However, a separate examination of the group of pupils with learning difficulties and the group of pupils with behaviour problems changed the results. While there was no relation between the social position and the social skills of pupils with learning difficulties, there was a significant relationship for pupils with behavioural problems. The authors concluded that a low level of empathy (i.e., exhibiting concern and respect for the feelings and viewpoint of others) might be an explanation of social difficulties only for pupils with behavioural problems. Further, Schwab et al. (2015) described a link between self-rated social participation and prosocial behaviour. Students with SEN (not specified) in secondary schools felt less socially included and reported lower levels of prosocial behaviour than their TD peers. Thus, the authors interpreted that the poor social participation of pupils with SEN might be associated with their reported low levels of prosocial behaviour.

This study attempts to contribute to the clarification of the relationship between the social skills and the social participation of pupils with SEN in general education classrooms. To obtain more focused findings, the sample of pupils with SEN consisted only of children with a diagnosed ID. These pupils were compared with selected TD peers with respect to social acceptance, social relationships, and self- and otheroriented social skills. The following research questions were addressed: 
a) How does the social participation of pupils with ID in general education classrooms appear in terms of social relationships and social acceptance?

b) How do peers and teachers rate the social skills of pupils with ID compared with popular, rejected, and isolated TD pupils?

c) Is there a relationship between the social participation of pupils with ID and their social skills?

\section{Method}

\subsection{Sample}

The sample consisted of 38 inclusive primary classrooms of the German- and French-speaking parts of Switzerland. A total of 692 first- to fourth-graders (aged $\mathrm{M}=97.92 ; \mathrm{SD}=10.51$ ) participated in the study. Only general education classrooms that included pupils with ID were allowed in the study. ${ }^{2}$ Therefore, in each classroom at least one pupil was officially diagnosed by a school psychologist as having ID. Based on this diagnosis special education resources were allocated to support these pupils ${ }^{3}$. In a first step, all 692 participants were individually interviewed regarding their social involvement in the classroom and the social skills of their peers. In a second step, popular, rejected, and isolated pupils were identified based on the collected data (for a detailed description, see the analyses). Finally, social skills and peer relationships were estimated by teachers for the selected TD pupils $(\mathrm{n}=89 ; 51.6 \%$ female $)$ and for the sample of pupils with ID $(\mathrm{n}=43 ; 39.5 \%$ female).

\subsection{Measures}

Social acceptance, social relationships, and social skills were assessed with teacher questionnaires and by individual pupil interviews. The instruments used for the interviews were developed and piloted to be suitable for pupils with ID.

\subsubsection{Social acceptance and social relationships}

To assess social acceptance, the rating method was applied. All pupils rated how much they liked to play with each classmate on a five-point-scale using smileys $(1=\theta=$ "I do not like to play with this classmate at all" to $5=(-)=$ "I like to play with this classmate a lot"). Each classmate's name was read to the participants and presented on an individual card.

The social relationships of pupils within the classroom were assessed using the nomination procedure. All participants were asked to nominate their regular playmates in the classroom ("With whom in your classroom do you play the most?"). The number of same- and cross-gender nominations was unlimited.

Teachers also estimated the social acceptance and relationships of the pupils. The teacher version of the Self- and Other-Oriented Social Competences questionnaire (SOCOMP; see Perren et al., 2012) includes the subscale positive peer relationships ( 5 items; $\alpha=0.89$ ). The items in this subscale primarily address

\footnotetext{
${ }^{2}$ Pupils with ID were full-time members of the general education classrooms. In each classroom, a special education teacher was present for four to 14 hours per week $(\mathrm{M}=7.22, \mathrm{SD}=3.36)$.

${ }^{3}$ The school psychologists applied the criterion IQ $<75$ to diagnose ID at the time of the data collection. Here, it is important to mention that IQ tests have their limitations when it comes to assessments of children with first language different from the test language or who are in a difficult affective state. In addition, a dichotomous categorisation of TD pupils and pupils with ID does not reflect disability as a social construct. Nevertheless, this categorisation is used in the present study because it is common in practice and affects processes of social participation.
} 
friendships (e.g., "Has at least one good friend") and social acceptance (e.g., "Is generally popular among peers").

\subsubsection{Social skills}

The social skills were rated by teachers and peers. The teachers were requested to estimate the social skills of their pupils with ID and selected TD pupils (popular, rejected, and isolated; for criteria, see 2.3.1) using the SOCOMP questionnaire. The teachers were not informed regarding the selection criteria of the TD pupils they rated, which means they were unaware of their sociometric status (popular, rejected, or isolated). All of the SOCOMP items were estimated on a three-point scale $(0=$ "not true at all" to $2=$ "definitely true"). Two dimensions of social skills were assessed: self-oriented social skills $(\alpha=0.88)$ with the three subscales leadership (3 items; e.g., "Organizes, suggests play activities to peers"), setting limits ( 3 items; e.g., "Refuses unreasonable requests from others"), and social participation (4 items; e.g., "Converses with peers easily"), and other-oriented social skills $(\alpha=0.88)$, including the two subscales prosocial (5 items; e.g., "Frequently helps other children") and cooperative behaviour (5 items; e.g., "Compromises in conflicts with peers").

The other-oriented social skills of the pupils were also estimated by peers with two questions regarding cooperative and prosocial behaviour $(\alpha=0.83)$. All of the participants rated on a five-point-scale with smileys $(1=:=$ "I do not agree at all" to $5=(;)=$ "I totally agree") four randomly selected classmates with respect to how well they could work with them and how helpful they were.

\subsection{Analyses}

\subsubsection{Social status}

Popular, rejected, and isolated pupils were selected for the study based on individual interviews with all of the participants. To identify popular and rejected pupils, the rating data were analysed. Pupils who received the highest score on the scale (5) from most of their peers (at least one standard deviation above average) were categorized as popular. Those pupils who received the lowest score on the scale (1) from most of their peers (at least one standard deviation above average) were categorized as rejected. To identify isolated pupils, indegree and outdegree scores were calculated based on the nomination data with UCINET (Borgatti, Everett, \& Freeman, 2002). Children who were not nominated by any classmate and did not nominate anyone as a playmate (indegree $=0=$ outdegree) were categorized as isolated. However, pupils were only identified as isolated if at least $80 \%$ of the pupils of the classroom had participated in the study. This cut-off criterion was established to respect the interdependency of network data (Huisman \& Steglich, 2008; Robins, Pattison, \& Woolcock, 2004).

Table 1 shows the distribution of sociometric status among TD pupils and pupils with ID. In 38 classrooms, 89 TD pupils were identified as popular, rejected, or isolated. In the case of 14 pupils, there was an overlap of the sociometric statuses "rejected" and "isolated". For $46.5 \%$ of the pupils with ID, a classification into status groups was possible. While most of these pupils were in the category rejected, five were identified as isolated and only one as popular. The rest of the pupils with ID (53.5\%) were "average", which means they were not rejected, isolated, or popular. 
Table 1

Sociometric status of pupils with ID and their TD peers

\begin{tabular}{lcccccc}
\hline Sample & n & Popular & Rejected & Isolated & Isolated and rejected & Average \\
\hline Pupils with ID & 43 & 1 & 14 & 4 & 1 & 23 \\
TD pupils & 89 & 38 & 19 & 18 & 14 & \\
\hline
\end{tabular}

\subsubsection{Social acceptance and social relationships}

Several scores for social acceptance (popularity and social rejection) and social relationships (number of friendships and at least one friend) were computed and standardized for each participant. Therefore, the rating data, the nomination data, and the subscale on positive peer relationships of the teacher questionnaire were analysed.

The rating data were used to calculate the scores for social acceptance. The popularity score consists of the sum of the highest rating on the scale (5) received by all classmates, whereas the social rejection score corresponds to the sum of the lowest ratings on the scale (1) received by all classmates. In addition, a mean score of social acceptance was calculated for each pupil with all ratings from 1 to 5 received by peers.

For each pupil, two social relationship scores were calculated. One was the number of reciprocated friendships. The other was a dichotomized score, which represents whether the pupil had at least one friend or none. According to the common practice, reciprocal nominations were defined as friendships (Hymel, Vaillancourt, McDougall, \& Renshaw, 2004). Because social network data are strongly influenced by the participant ratio, the values were divided by the maximum number of possible friendships in the classroom $((n *(n-1)) / 2)$.

The teacher's view of the social relationships and social acceptance of the pupils was represented with standardized sums of the SOCOMP dimension of positive peer relationships.

\subsubsection{Social skills}

The social skills were estimated by teachers and peers. For the teacher's perspective, the standardized sums of the two dimensions self- and other-oriented social skills of the SOCOMP questionnaire were calculated for each pupil. Based on the peer ratings regarding the cooperative and prosocial behaviour of classmates, a standardized mean score was calculated for each pupil. This score represents the otheroriented social skills from the peer's perspective.

\section{Results}

\subsection{Social acceptance and social relationships}

Practically all popular TD children had at least one friend and on average the highest number of friends compared with the other pupils (Table 2). In addition, more than half of the rejected TD pupils had friends. A majority of the pupils with ID (63\%) had at least one reciprocal friend. Interestingly, this was the case for most of the rejected and for most of the average pupils with ID but not for the only popular pupil in this sample. 
Table 2

Friendships of pupils with ID and their TD peers

\begin{tabular}{llcc}
\hline & \multicolumn{2}{c}{ Friendships } \\
\hline Group & n & M (SD) & At least one friend (\%) \\
\hline Pupils with ID & 43 & $.98(1.08)$ & $27(63)$ \\
$\quad$ Popular & 1 & & $10(71)$ \\
Rejected & 14 & $.71(.47)$ & $17(74)$ \\
Average & 23 & $1.39(1.27)$ & $48(54)$ \\
TD pupils & 89 & $1.18(1.48)$ & $35(92)$ \\
Popular & 38 & $2.32(1.53)$ & $13(68)$ \\
Rejected & 19 & $.89(.83)$ & \\
\hline
\end{tabular}

Isolated pupils are not represented in this table.

\subsection{Social skills}

The relationship between the social skills of pupils with ID, their sociometric status, and their friendships were analysed with nonparametric tests and correlations. In a first step, comparisons within the status groups of pupils with ID and of TD pupils were performed. In a second step, status groups of pupils with ID were compared with status groups of TD pupils.

\subsubsection{Pupils with ID}

According to teacher reports, popular and accepted pupils with ID $(\mathrm{n}=24)$ did not differ significantly from rejected and isolated pupils with ID $(n=19)$ in their social skills (Table 3). In addition, only weak correlations were found between the mean acceptance score of pupils with ID and their selforiented $(\mathrm{r}=0.119)$ and other-oriented $(\mathrm{r}=0.197)$ social skills. However, differences were found with respect to their positive peer relationships $(U=103.50, z=-3.07, p=0.002)$. Consistent with their sociometric status, rejected and isolated pupils with ID were estimated by teachers to be less accepted and less popular among their peers. Additionally, these pupils were perceived by their peers as having lower levels of other-oriented social skills $(U=140.00, z=-2.15, p=0.031)$ than the popular and accepted pupils with ID. In line with this result, the correlation between the other-oriented social skills rated by peers and the mean acceptance score was high $(\mathrm{r}=0.662)$. However, rejected and isolated pupils with ID did not have significantly fewer friends than popular and accepted pupils with ID.

For further analyses, the sample of pupils with ID was split into two groups: pupils with at least one friend ( $\mathrm{n}=27 ; 62 \%$ accepted and $37 \%$ rejected) and pupils without friends $(\mathrm{n}=16 ; 62 \%$ accepted and/or isolated, 31\% rejected, and 6\% popular). Regarding social acceptance and rejection, the two groups did not differ significantly. In addition, based on peer and teacher estimations, no significant differences were found regarding self-oriented or other-oriented skills. Surprisingly, the groups were also similar in their positive peer relationships reported by teachers. There was only a significant difference regarding the item "Has at least one good friend" ( $\mathrm{U}=127.00, \mathrm{z}=-2.52, \mathrm{p}=0.012)$, which indicates that teachers notice when pupils with ID do not have friends. 
Table 3

Social skills mean values (SD) of pupils with ID

\begin{tabular}{llccc}
\hline & & \multicolumn{2}{c}{ Teacher-reported } & Peer-reported \\
\hline Group & $\mathbf{n}$ & Self-oriented & Other-oriented & Other-oriented \\
\hline Pupils with ID & 43 & $9.35(3.92)$ & $11.53(4.39)$ & $3.08(.77)$ \\
Popular \& average & 24 & $10.29(4.20)$ & $12.42(4.37)$ & $3.35(.62)$ \\
Rejected \& isolated & 19 & $8.58(3.42)$ & $10.42(4.27)$ & $2.74(.82)^{*}$ \\
With friends & 27 & $9.52(3.98)$ & $11.63(4.85)$ & $3.09(.71)$ \\
Without friends & 16 & $9.56(3.97)$ & $11.38(3.63)$ & $3.06(.89)$
\end{tabular}

The values displayed are not standardised. The teacher-reported values reported range from 0 to 20 , and the peerreported values range from 1 to 5 . The indicated significant differences refer to a comparison with the value in the row above $(* \mathrm{p}<0.05)$.

\subsubsection{TD pupils}

According to the teacher reports, popular TD pupils $(\mathrm{n}=38)$ had significantly higher levels of selforiented social skills $(\mathrm{U}=588.50, \mathrm{z}=-3.16, \mathrm{p}=0.002)$, other-oriented social skills $(\mathrm{U}=305.50, \mathrm{z}=-5.53, \mathrm{p}$ $=0.000)$, and positive peer relationships $(\mathrm{U}=142.50, \mathrm{z}=-6.98, \mathrm{p}=0.000)$ than rejected and isolated TD pupils $(\mathrm{n}=51)$. Additionally, rejected and isolated TD pupils had fewer friends $(\mathrm{U}=312.50, \mathrm{z}=-6.60, \mathrm{p}=$ $0.000)$ and were estimated by peers as exhibiting a lower level of other-oriented social skills $(\mathrm{U}=107.00, \mathrm{z}$ $=-7.15, \mathrm{p}=0.000$ ) than popular TD pupils (Table 4). In addition, high correlations were found between the mean acceptance score and the other-oriented social skills reported by teachers $(r=0.616)$ and by peers (0.727). However, the correlation between the mean acceptance score and the self-oriented social skills was low $(\mathrm{r}=0.254)$.

There were significant differences between TD pupils with at least one friend $(\mathrm{n}=48 ; 73 \%$ popular and $27 \%$ rejected) and without friends $(\mathrm{n}=41 ; 48 \%$ rejected, $43 \%$ isolated, and $7 \%$ popular). TD pupils with friends were estimated by teachers as having higher self-oriented $(\mathrm{U}=1406.50, \mathrm{z}=3.49, \mathrm{p}=0.000)$ and other-oriented social skills $(\mathrm{U}=1449.00, \mathrm{z}=3.85, \mathrm{p}=0.000)$. Similar results emerged regarding peerreported other-oriented social skills $(\mathrm{U}=1504.50, \mathrm{z}=4.28, \mathrm{p}=0.000)$. Thus, according to teacher and peer reports, TD pupils without friends tend to be less socially competent than TD pupils with friends. In addition, the teacher reports displayed differences regarding positive peer relationships $(\mathrm{U}=1578.50, \mathrm{z}=4.98, \mathrm{p}=$ 0.000). This outcome indicates that teachers notice when pupils do or do not have friends.

Additionally, TD pupils with and without friends differed significantly with respect to social acceptance $(U=1611.00, z=5.16, p=0.000)$ and rejection $(U=626.00, z=-2.82, p=0.005)$. Thus, popular TD pupils tend to have friends, whereas rejected TD pupils tend to be friendless. These accentuated results might have appeared because the subsample consists of pupils of extreme status groups: the most popular and the most rejected pupils in the classroom. This fact must be considered when interpreting the results. 
Table 4

Social skills mean values (SD) of TD pupils

\begin{tabular}{llccc}
\hline & & \multicolumn{2}{c}{ Teacher-reported } & Peer-reported \\
\hline Group & $\mathbf{n}$ & Self-oriented & Other-oriented & Other-oriented \\
\hline TD pupils & 89 & $13.02(5.42)$ & $14.03(5.15)$ & $3.60(.97)$ \\
Popular & 38 & $15.08(4.56)$ & $17.50(3.11)$ & $4.35(.56)$ \\
Rejected \& isolated & 51 & $11.49(5.54)^{* *}$ & $11.45(4.86)^{* * *}$ & $3.04(.82)^{* * *}$ \\
With friends & 48 & $14.90(4.57)$ & $15.92(4.58)$ & $3.97(.83)$ \\
Without friends & 41 & $10.83(5.55)^{* * * *}$ & $11.78(4.91)^{* * *}$ & $3.17(.94)^{* * * *}$ \\
\hline
\end{tabular}

The values displayed are not standardised. The teacher-reported values range from 0 to 20, and the peer-reported values range from 1 to 5 . The indicated significant differences refer to a comparison with the value in the row above $(* * * \mathrm{p}<0.001 . * * \mathrm{p}<0.01)$

\subsubsection{Comparison of pupils with ID with TD pupils}

Compared with rejected TD pupils $(n=19)$, rejected pupils with ID $(n=14)$ had a significantly lower level of self-oriented social skills $(U=54.50, z=-2.87, p=0.003$; Table 5). However, they did not differ with respect to their other-oriented social skills and positive peer relationships reported by their teachers. In addition, the result of a comparison of all pupils with ID $(n=43)$ with the rejected and/or isolated TD pupils $(n=51)$ revealed no significant differences regarding social skills, whereas regarding social relationships, a difference was found: an advantage for pupils with ID. The teachers estimated the positive peer relationships of pupils with ID on a higher level than of rejected and/or isolated TD pupils (U $=$ $777.00, \mathrm{z}=-2.44, \mathrm{p}=0.015)$. In addition, pupils with ID had significantly more friends than rejected and/or isolated TD pupils $(\mathrm{U}=660.50, \mathrm{z}=-3.68, \mathrm{p}=0.000)$.

Table 5

Social skills mean values (SD) of pupils with ID and TD pupils

\begin{tabular}{llccc}
\hline & \multicolumn{2}{c}{ Teacher-reported } & Peer-reported \\
\hline Group & $\mathbf{n}$ & Self-oriented & Other-oriented & Other-oriented \\
\hline $\begin{array}{l}\text { Rejected pupils with ID } \\
\text { vs. }\end{array}$ & 14 & $7.93(3.45)$ & $10.93(4.51)$ & $2.71(.78)$ \\
$\quad$ Rejected TD pupils & 19 & $13.26(5.34)^{* *}$ & $10.79(4.76)$ & $2.95(.77)$ \\
$\begin{array}{l}\text { Pupils with ID } \\
\text { vs. }\end{array}$ & 43 & $9.35(3.92)$ & $11.53(4.39)$ & $3.08(.77)$ \\
$\quad \begin{array}{l}\text { Popular TD pupils } \\
\quad \text { Rejected \& isolated TD pupils }\end{array}$ & 51 & $11.49(5.54)$ & $11.45(4.86)$ & $4.35(.56)^{* * *}$ \\
\hline
\end{tabular}

The values displayed are not standardised. The teacher-reported values range from 0 to 20 , and the peer-reported values range from 1 to $5 . * * * \mathrm{p}<0.001 . * * \mathrm{p}<0.01$.

A different set of results emerged from the comparison of pupils with ID $(n=43)$ with popular TD pupils $(n=38)$. Significant differences in all aspects were found. The pupils with ID were estimated to have lower levels of self-oriented social skills $(U=295.00, z=-4.95, p=0.000)$, other-oriented social skills $(U=$ 
$212.00, \mathrm{z}=-5.75, \mathrm{p}=0.000)$, positive peer relationships $(\mathrm{U}=169.00, \mathrm{z}=-6.29, \mathrm{p}=0.000)$, and peerreported other-oriented social skills $(\mathrm{U}=99.00, \mathrm{z}=-6.79, \mathrm{p}=0.000)$ than popular TD pupils. In addition, pupils with ID had significantly fewer friends than popular TD pupils $(U=162.50, z=-6.19, p=0.000)$.

Finally, a Fishers' $z$-Test was performed to compare pupils with ID $(n=43)$ with their TD peers $(n=$ 89) regarding the correlations between social acceptance and social skills. Only the correlation between social acceptance and the other-oriented social skills rated by the teachers was significantly higher $(\mathrm{Z}=$ $2.711, p=0.003)$ in the group of TD pupils $(r=0.616)$ than in the group of pupils with ID $(r=0.197)$. This result indicates that pupils with ID are not less accepted if they have lower levels of other-oriented social skills. In contrast, socially accepted TD pupils have higher levels of other-oriented social skills. In addition, the correlations between other-oriented social skills rated by peers and social acceptance were high for both groups and in turn did not differ significantly. This outcome means that for pupils with ID as well as for TD pupils being socially accepted was related to being perceived by peers as being helpful and cooperative. In contrast, for both groups, the self-oriented social skills were weakly correlated with social acceptance.

\section{Discussion}

Until now, little was known regarding the social participation of pupils with ID enrolled in general education classrooms. In addition, no studies have investigated the role that social skills may play in social participation. This study contributes to clarifying the relationship between the social skills and the social participation of pupils with ID in inclusive classrooms. Therefore, the social relationships and social acceptance of these pupils were analysed in relation to their self- and other-oriented social skills. In addition, a comparison of social skills was performed between pupils with ID and TD pupils experiencing a more or less positive social participation.

This study reveals that most pupils with ID enrolled in inclusive classrooms were not popular but were accepted by their peers. In addition, a majority of these pupils, including those who were rejected, had reciprocal friends. These findings agree with studies which report that not all pupils with SEN are at risk of being isolated or rejected in general education classrooms (e.g., Avramidis, 2013; Frostad, Mjaavatn, \& Pijl, 2011; Frostad \& Pij1, 2007; Grütter et al., 2015; Koster et al., 2010; Schwab, 2015).

Regarding social skills, in this study, pupils with ID were generally less socially competent than their TD peers. However, no significant association was found with having friends. Pupils with ID who had friends exhibited a similar level of social skills as pupils with ID who were isolated or did not have reciprocal friendships. Thus, it seems that their ability to form and maintain friendships was not influenced by a lack of social skills, and they even appear to possess skills that benefit interaction with peers. According to the literature, children require a number of basic social skills to form friendships (Gest, Graham-Bermann, \& Hartup, 2001; Sebanc, 2003). Thus, it seems that the majority of the pupils with ID in this sample must possess these basic social skills. This finding is promising because peer relationships can positively contribute to the socio-emotional adjustment of children (Gifford-Smith \& Brownell, 2003; Murray \& Greenberg, 2006).

In addition, the social skills of pupils with ID were not always related to their social acceptance. From the perspective of peers, rejected pupils with ID were estimated as being less cooperative and prosocial than accepted pupils with ID. However, from the perspective of teachers, the social skills of rejected pupils with ID did not differ from those of accepted pupils with ID. Similar results were presented in a study by Frostad and Pijl (2007), who found no significant relationship between the social skills of pupils with learning disabilities and their social acceptance or their social relationships. In addition, the two variables were only weakly related when the entire sample of pupils with and without SEN was analysed. However, pupils with SEN had lower levels of social skills than their TD peers. 
In this study, pupils with ID were also compared regarding their social skills with TD pupils experiencing more or less difficulties in their social participation in classroom. While the social participation of popular TD pupils seemed to be satisfactory, rejected and isolated TD pupils experienced difficulties in their social participation.

In a first step, the rejected and isolated TD pupils were compared with the entire sample of pupils with ID. As expected, there were no differences between the two groups with respect to social skills. However, pupils with ID had fewer difficulties in building and maintaining social relationships than rejected and isolated TD pupils. This outcome means that although pupils with ID had levels of social skills similarly low to those of their rejected and isolated TD peers, they tended to have more friends. However, the latter finding could be biased because isolated pupils are friendless by definition. Thus, only rejected pupils with ID and rejected TD pupils were compared. These two groups displayed similarities in their peer relationships and their other-oriented social skills. However, rejected pupils with ID had lower levels of self-oriented social skills than their rejected TD peers. Based on these results, the obvious conclusion is that pupils with ID can experience more positive social relationships than certain of their TD peers but tend to have more difficulties in setting limits, initiating social interactions and leading than their rejected TD peers. Otherwise, the pupils with ID have levels of social skills similarly low to those of their rejected and isolated TD peers. This result means that in general education classrooms not only pupils with SEN but also certain of their TD peers lack social skills and can therefore also be at risk of social exclusion. Consequently, interventions to foster social participation should not only focus on pupils with SEN but also should involve the entire class. In fact, peer-mediated learning activities that involve all pupils can positively influence the social interactions in inclusive classrooms (Fuchs, Fuchs, Mathes, \& Martinez, 2002; Jacques, Wilton, \& Townsend, 1998).

In a second step, a comparison between pupils with ID and popular TD pupils was performed. Significant differences between the two groups were found. Pupils with ID had fewer friends and exhibited lower levels of self- and other-oriented social skills than popular TD pupils. This contrast between the two groups was perhaps because practically none of the pupils with ID were popular. Consequently, it could be argued that pupils with ID are not as popular as certain of their TD peers because of their lack of social skills. On one hand, a strong positive relationship was found between the level of other-oriented social skills and the social acceptance of TD pupils. This outcome could indicate that for TD pupils providing particular consideration to the needs and goals of others can positively influence their social acceptance or popularity in a group. A similar finding was reported by Gest et al. (2001). In their study, children who were perceived by teachers and peers as socially skilled were more popular among peers. On the other hand, among pupils with ID, there was a weak relationship between social skills and social acceptance. More specifically, only peer rated other-oriented social skills were related to social acceptance, but not self- and other-oriented social skills reported by teachers. That is, if pupils with ID were rejected by their peers, it was probably not only because of their low level of social skills. Thus, there must be other mechanisms influencing the social participation of pupils with ID in inclusive classrooms, for example, the achievement level of these pupils. In fact, Krull et al. (2014) and Nepi et al. (2015) found a relationship between low academic achievement levels and low social acceptance by peers. Further, on a group level, classroom composition and group norms can also play a crucial role regarding the social participation of individuals in inclusive classrooms (Garrote, 2016; Grütter et al., 2015). But, additional studies are required to support these findings.

The findings of this study are a contribution to current knowledge on the social participation and the social skills of pupils with ID in inclusive classrooms. Nevertheless, several limitations of this study should be mentioned. First, a specific concept of social skills was chosen. While such a choice makes the findings more conclusive within a study, comparisons with other studies using different concepts are challenging. Second, when interpreting the results, it must be considered that correlations between aspects of social participation and social skills might appear because of overlapping concepts. For example, the aspect of social interactions can be found (in a different function) in relation to the assessment of social skills and of social participation. Third, the high correlations between social acceptance and peer-rated other-oriented social skills might result from the assessment method. Participants were requested to rate how much they liked to play with their classmates. Subsequently, they rated how helpful their classmates were and how well 
they could work with them. If we consider the cognitive process of dissonance (Festinger, 1957), it is expected that pupils will rate their classmates consistently or that the two variables will correlate highly. Fourth, in this study, groups were compared regarding social skills. The question of which basic social skills pupils with SEN require to have friends or be accepted by their peers remains unanswered. Fifth, pupils with ID were compared to TD pupils of extreme status groups: the most popular and the most rejected pupils in the classroom. This was due to the study design, in which detailed data collection was restricted to a number of pupils in the sample. Sixth, a dichotomous categorisation of pupils with ID and TD pupils was used to investigate possible hindering factors in the social participation of pupils with ID. Although, this categorisation does not reflect disability as a social construct, it is commonly used in practice to allocate special education resources to support individual pupils. In addition, how special educational support is implemented (e.g., in a resource-room) can enhance the perception of pupils with ID as an out-group and influence processes of social participation in inclusive classrooms. To shed light into social processes influenced by this dichotomy used in practice further studies are needed.

In conclusion, the findings support the assumption that social skills are only one possible explanation why certain pupils with ID are more at risk of being less socially involved in their classrooms than their TD peers. Having friends or being rejected did not seem to depend on the low level of social skills of pupils with ID. Thus, there must be other factors that have a stronger influence on the social participation of these pupils. Possible factors may be identified on the individual level (e.g., having the label "ID"). However, group processes should be considered as well. Focusing on group processes rather than on individual characteristics has been a promising approach regarding the development and evaluation of interventions to foster social interactions among pupils with and without SEN (Whalon et al., 2015). Indeed, facilitating social participation requires the effort and engagement of all, including peers and teachers (Farmer, McAuliffe Lines, \& Hamm, 2011; Garrote, Sermier Dessemontet, \& Moser Opitz, 2017; Gest \& Rodkin, 2011). This change of perspective could also be beneficial for research on social participation. This approach demands from researchers focusing more on variables on classroom or group level rather than solely on individual characteristics. In fact, social participation of individuals in inclusive classrooms is very likely to vary as a function of group and individual factors.

\section{Keypoints}

- Most pupils with ID have friends and are accepted by classmates in inclusive classrooms.

- Generally, social skills might play a role in the social participation of pupils but are not the only influencing factor.

- For pupils with ID in primary classrooms, high levels of self-oriented and other-oriented social skills are not necessary to be socially accepted and have friends.

\section{Acknowledgements}

This work was supported by the Swiss National Science Foundation [grant number 146086].

\section{References}

Avramidis, E. (2013). Self-concept, social position and social participation of pupils with SEN in mainstream primary schools. Research Papers in Education, 28(4), 421-442. doi:10.1080/02671522.2012.673006 
Bellini, S., Peters, J. K., Benner, L., \& Hopf, A. (2007). A meta-analysis of school-based social skills interventions for children with autism spectrum disorders. Remedial and Special Education, 28(3), 153162. doi: $10.1177 / 07419325070280030401$

Borgatti, S. P., Everett, M. G., \& Freeman, S. F. (2002). UCINET 6 for Windows: Software for Social Network Analysis. Natick: Analytic Technologies, Inc.

Bossaert, G., Colpin, H., Pijl, S. J., \& Petry, K. (2013). Truly included? A literature study focusing on the social dimension of inclusion in education. International Journal of Inclusive Education, 17(1), 60-79. doi:10.1080/13603116.2011.580464

Camargo, S., Rispoli, M., Ganz, J., Hong, E., Davis, H., \& Mason, R. (2014). A review of the quality of behaviorally-based intervention research to improve social interaction skills of children with ASD in inclusive settings. Journal of Autism and Developmental Disorders, 44(9), 2096-2116. doi:10.1007/s10803-014-2060-7

Estell, D. B., Jones, M. H., Pearl, R., van Acker, R., Farmer, T. W., \& Rodkin, P. C. (2008). Peer groups, popularity, and social preference: Trajectories of social functioning among students with and without learning disabilities. Journal of Learning Disabilities, 41(1), 5-14. doi:10.1177/0022219407310993

Fabes, R. A., Martin, C. L., \& Hanish, L. D. (2009). Children's behaviors and interactions with peers. In K. H. Rubin, W. M. Bukowski, \& B. P. Laursen (Eds.), Social, emotional, and personality development in context. Handbook of peer interactions, relationships, and groups (pp. 45-62). New York: Guilford Press.

Farmer, T. W., McAuliffe Lines, M., \& Hamm, J. V. (2011). Revealing the invisible hand: The role of teachers in children's peer experiences. Journal of Applied Developmental Psychology, 32(5), 247-256. doi:10.1016/j.appdev.2011.04.006

Feldman, R., Carter, E. W., Asmus, J., \& Brock, M. E. (2015). Presence, proximity, and peer interactions of adolescents with severe disabilities in general education classrooms. Exceptional Children, 82(2), 192208. doi:10.1177/0014402915585481

Festinger, L. (1957). A theory of cognitive dissonance. Stanford, California: Stanford University Press.

Frederickson, N., \& Turner, J. (2003). Utilizing the classroom peer group to adress children's social needs: An evaluation of the circle of friends intervention approach. The Journal of Special Education, 36(4), 234-245.

Frostad, P., Mjaavatn, P. E., \& Pijl, S. J. (2011). The stability of social relations among adolescents with special educational needs (SEN) in regular schools in Norway. London Review of Education, 9(1), 8394. doi:10.1080/14748460.2011.550438

Frostad, P., \& Pijl, S. J. (2007). Does being friendly help in making friends? The relation between the social position and social skills of pupils with special needs in mainstream education. European Journal of Special Needs Education, 22(1), 15-30. doi:10.1080/08856250601082224

Fuchs, D., Fuchs, L. S., Mathes, P. G., \& Martinez, E. A. (2002). Preliminary evidence on the social standing of students with learning disabilities in PALS and no-PALS classrooms. Learning Disabilities Research \& Practice, 17(4), 205-215. doi:10.1111/1540-5826.00046

Garrote, A. (2016). Soziale Teilhabe von Kindern in inklusiven Klassen. Empirische Pädagogik, 30(1), 6780.

Garrote, A., Sermier Dessemontet, R., \& Moser Opitz, E. (2017). Facilitating the social participation of pupils with special educational needs in mainstream schools: A review of school-based interventions. Educational Research Review, 20, 12-23. doi:10.1016/j.edurev.2016.11.001

Gest, S. D., Graham-Bermann, S. A., \& Hartup, W. W. (2001). Peer experience: Common and unique features of number of friendships, social network centrality, and sociometric status. Social Development, 10(1), 23-40. doi:10.1111/1467-9507.00146

Gest, S. D., \& Rodkin, P. C. (2011). Teaching practices and elementary classroom peer ecologies. Journal of Applied Developmental Psychology, 32(5), 288-296. doi:10.1016/j.appdev.2011.02.004

Gifford-Smith, M. E., \& Brownell, C. A. (2003). Childhood peer relationships: Social acceptance, friendships, and peer networks. Journal of School Psychology, 41(4), 235-284. doi:10.1016/S00224405(03)00048-7 
Goldstein, H., English, K., Shafer, K., \& Kaczmarek, L. (1997). Interaction among preschoolers with and without disabilities: effects of across-the-day peer intervention. Journal of Speech, Language \& Hearing Research, 40(1), 33-48. from $\mathrm{http}: / /$ search.ebscohost.com/login.aspx?direct $=$ true $\& \mathrm{db}=\mathrm{c} 8 \mathrm{~h} \& \mathrm{AN}=1998076502 \&$ site $=$ ehost-live

Gresham, F. M., \& MacMillan, D. L. (1997). Social competence and affective characteristics of students with mild disabilities. Review of Educational Research, 67(4), 377-415. Retrieved from http://www.jstor.org/stable/1170514

Groeben, M., Perren, S., Stadelmann, S., \& Klitzing, K. (2011). Emotional symptoms from kindergarten to middle childhood: Associations with self- and other-oriented social skills. European Child \& Adolescent Psychiatry, 20(1), 3-15. doi:10.1007/s00787-010-0139-z

Grütter, J., Meyer, B., \& Glenz, A. (2015). Sozialer Ausschluss in Integrationsklassen: Ansichtssache? Psychologie in Erziehung und Unterricht, 62(1), 65. doi:10.2378/peu2015.art05d

Henricsson, L., \& Rydell, A.-M. (2006). Children with behaviour problems: The influence of social competence and social relations on problem stability, school achievement and peer acceptance across the first six years of school. Infant and Child Development, 15(4), 347-366. doi:10.1002/icd.448

Huber, C. (2006). Soziale Integration in der Schule?!: Eine empirische Untersuchung zur sozialen Integration von Schülern mit sonderpädagogischem Förderbedarf im Gemeinsamen Unterricht. Marburg: Tectum-Verlag.

Huber, C., \& Wilbert, J. (2012). Soziale Ausgrenzung von Schülern mit sonderpädagogischem Förderbedarf und niedrigen Schulleistungen im gemeinsamen Unterricht. Empirische Sonderpädagogik, (2), 147165.

Huisman, M., \& Steglich, C. (2008). Treatment of non-response in longitudinal network studies. Social Networks, 30(4), 297-308. doi:10.1016/j.socnet.2008.04.004

Hymel, S., Vaillancourt, T., McDougall, P., \& Renshaw, P. (2004). Peer acceptance and rejection in childhood. In P. K. Smith \& C. H. Hart (Eds.), Blackwell handbook of childhood social development. Oxford, UK: Blackwell Publishing Ltd.

Jacques, N., Wilton, K., \& Townsend, M. (1998). Cooperative learning and social acceptance of children with mild intellectual disability. Journal of Intellectual Disability Research, 42(1), 29-36. doi:10.1046/j.1365-2788.1998.00098.x

Kamps, D., Royer, J., Dugan, E., Kravits, T., Gonzalez-Lopez, A., Garcia, J., . . Garrison Kane, L. (2002). Peer training to facilitate social interaction for elementary students with autism and theirs peers. Council for Exceptional Children, 68(2), 173-187.

Kavale, K. A., \& Forness, S. R. (1996). Social skill deficits and learning disabilities: A meta-analysis. Journal of Learning Disabilities, 29(3), 226-237. doi:10.1177/002221949602900301

Koster, M., Nakken, H., Pijl, S. J., \& van Houten, E. (2009). Being part of the peer group: A literature study focusing on the social dimension of inclusion in education. International Journal of Inclusive Education, 13(2), 117-140. doi:10.1080/13603110701284680

Koster, M., Pijl, S. J., Nakken, H., \& van Houten, E. (2010). Social participation of students with special needs in regular primary education in the Netherlands. International Journal of Disability, Development and Education, 57(1), 59-75. doi:10.1080/10349120903537905

Krull, J., Wilbert, J., \& Hennemann, T. (2014). Soziale Ausgrenzung von Erstklässlerinnen und Erstklässlern mit sonderpädagogischem Förderbedarf im Gemeinsamen Unterricht. Empirische Sonderpädagogik, $6(1), 59-75$.

Malti, T., \& Perren, S. (Eds.). (2016). Soziale Kompetenz bei Kindern und Jugendlichen: Entwicklungsprozesse und Förderungsmöglichkeiten (2nd ed.). Stuttgart: Kohlhammer.

Monchy, M. de, Pijl, S. J., \& Zandberg, T. (2004). Discrepancies in judging social inclusion and bullying of pupils with behaviour problems. European Journal of Special Needs Education, 19(3), 317-330. doi: $10.1080 / 0885625042000262488$

Murray, C., \& Greenberg, M. T. (2006). Examining the importance of social relationships and social contexts in the lives of children with high-incidence disabilities. The Journal of Special Education, 39(4), 220-233. doi:10.1177/00224669060390040301 
Nepi, L. D., Fioravanti, J., Nannini, P., \& Peru, A. (2015). Social acceptance and the choosing of favourite classmates: a comparison between students with special educational needs and typically developing students in a context of full inclusion. British Journal of Special Education, n/a. doi:10.1111/14678578.12096

Perren, S., Argention-Groeben, M., Stadelmann, S., \& Klitzing, K. von. (2016). Selbst- und fremdbezogene soziale Kompetenzen: Auswirkungen auf das emotionale Befinden. In T. Malti \& S. Perren (Eds.), Soziale Kompetenz bei Kindern und Jugendlichen. Entwicklungsprozesse und Förderungsmöglichkeiten (2nd ed., pp. 91-110). Stuttgart: Kohlhammer.

Perren, S., Forrester-Knauss, C., \& Alsaker, F. D. (2012). Self- and other-oriented social skills: Differential associations with children's mental health and bullying roles. Journal for Educational Research Online / Journal für Bildungsforschung Online; Vol 4, No 1 (2012): Assessment and development of social competence, (1), 99-123. Retrieved from http://www.j-e-r-o.com/index.php/jero/article/view/306

Pijl, S. J., \& Frostad, P. (2010). Peer acceptance and self-concept of students with disabilities in regular education. European Journal of Special Needs Education, 25(1), 93-105. doi:10.1080/08856250903450947

Pijl, S. J., Frostad, P., \& Flem, A. (2008). The social position of pupils with special needs in regular schools. Scandinavian Journal of Educational Research, 52(4), 387-405. doi:10.1080/00313830802184558

Robins, G., Pattison, P., \& Woolcock, J. (2004). Missing data in networks: exponential random graph ( $\mathrm{p}_{*}$ ) models for networks with non-respondents. Social Networks, 26(3), 257-283. doi:10.1016/j.socnet.2004.05.001

Rose-Krasnor, L. (1997). The nature of social competence: A theoretical review. Social Development, 6(1), 111-135. doi:10.1111/j.1467-9507.1997.tb00097.x

Rotheram-Fuller, E., Kasari, C., Chamberlain, B., \& Locke, J. (2010). Social involvement of children with autism spectrum disorders in elementary school classrooms. Journal of Child Psychology and Psychiatry, 51(11), 1227-1234. doi:10.1111/j.1469-7610.2010.02289.x

Rubin, K. H., Bukowski, W. M., \& Parker, J. G. (2006). Peer interactions, relationships, and groups. In N. Eisenberg (Ed.), Handbook of child psychology (6th ed., pp. 571-645). Hoboken, N.J: John Wiley \& Sons.

Ruijs, N. M., \& Peetsma, T. T. D. (2009). Effects of inclusion on students with and without special educational needs reviewed. Educational Research Review, 4(2), 67-79. doi:10.1016/j.edurev.2009.02.002

Schwab, S. (2015). Social dimensions of inclusion in education of 4th and 7th grade pupils in inclusive and regular classes: Outcomes from Austria. Research in Developmental Disabilities, 43-44, 72-79. doi:10.1016/j.ridd.2015.06.005

Schwab, S., Gebhardt, M., Krammer, M., \& Gasteiger-Klicpera, B. (2015). Linking self-rated social inclusion to social behaviour. An empirical study of students with and without special education needs in secondary schools. European Journal of Special Needs Education, 30(1), 1-14. doi:10.1080/08856257.2014.933550

Sebanc, A. M. (2003). The friendship features of preschool children: Links with prosocial behavior and aggression. Social Development, 12(2), 249-268. doi:10.1111/1467-9507.00232

United Nations (2006). Convention on the rights of persons with disabilities and optional protocol. New York: United Nations.

Whalon, K. J., Conroy, M. A., Martinez, J. R., \& Werch, B. L. (2015). School-based peer-related social competence interventions for children with autism spectrum disorder: A meta-analysis and descriptive review of single case research design studies. Journal of Autism and Developmental Disorders, 45(6), 1513-1531. doi:10.1007/s10803-015-2373-1 